\title{
Efficacy of the epidural blood patch for the treatment of post
} lumbar puncture headache BLOPP: A randomised, observer-blind, controlled clinical trial [ISRCTN 7/598245]

\author{
R Oedit $^{\dagger 1}$, F van Kooten*11, SLM Bakker ${ }^{\dagger 2}$ and DWJ Dippel ${ }^{\dagger 1}$
}

Address: ${ }^{1}$ Erasmus Medical Centre, Rotterdam, The Netherlands and ${ }^{2}$ Amphia General Hospital, Breda/Oosterhout, The Netherlands

Email: R Oedit - r.oedit@erasmusmc.nl; F van Kooten* - f.vankooten@erasmusmc.nl; SLM Bakker - sbakker@amphia.nl; DWJ Dippel - d.dippel@erasmusmc.nl

* Corresponding author †Equal contributors

Published: 05 July 2005

BMC Neurology 2005, 5:12 doi:10.1 186/147|-2377-5-12
Received: 27 May 2005

Accepted: 05 July 2005

This article is available from: http://www.biomedcentral.com/I47/-2377/5//2

(c) 2005 Oedit et al; licensee BioMed Central Ltd.

This is an Open Access article distributed under the terms of the Creative Commons Attribution License (http://creativecommons.org/licenses/by/2.0), which permits unrestricted use, distribution, and reproduction in any medium, provided the original work is properly cited.

\begin{abstract}
Background: Post dural punction headache (PDPH) occurs in $10 \%$ to $40 \%$ of the patients who had a lumbar puncture. Its symptoms can be severe and incapacitating. The epidural blood patch is widely accepted as the treatment of choice for postdural puncture headache. Uncontrolled studies report rapid recovery after patching in $90 \%$ to $100 \%$ of treated patients. However, sufficient evidence from randomised, controlled clinical trials is lacking.

Methods: BLOPP (blood patch for post dural puncture headache) is a randomised, single centre, observer-blind clinical trial. Patients with PDPH for at least 24 hours and at most 7 days after lumbar puncture will be randomised to treatment with an epidural blood patch (EDBP) or to conventional treatment, i.e. 24 hours bed rest and ample fluid intake. PDPH 24 hours after treatment, classified on a 4-point scale (no, mild, moderate, severe) is the primary outcome. The secondary outcome is the presence of PDPH 7 days after treatment. We estimated that a sample size of $2 \times 20$ patients would provide us with a power of $80 \%$ to detect a relative reduction in number of patients with persisting PDPH after 24 hours of $50 \%$ at the usual significance level $\alpha=$ $5 \%$, taking into account that in approximately $10 \%$ of the patients the PDPH will have resolved spontaneously after one day.

Discussion: The EDBP is accepted as the treatment of choice for PDPH although randomised, controlled data is scarce. Our randomised, observer-blind clinical trial enables us to compare the efficacy of two clinically practiced methods of PDPH treatment; EDBP versus conventional treatment, as they are applied in clinical practise.
\end{abstract}

\section{Background}

Headache complicates approximately 10 to $40 \%$ of dural punctures [1]. This postdural puncture headache (PDPH) is typically orthostatic; provoked or aggravated by a vertical or upright position and relieved by a horizontal position. PDPH is probably caused by cerebral spinal fluid leakage through the dural rent, into the epidural space. The leakage causes a decrease in CSF pressure and volume, leading to traction on pain-sensitive structures in an upright position. Besides of headache, the patient may complain of diplopia, tinnitus, dizziness, and myalgia. PDPH may occur immediately after spinal tap, but it starts 
within 48 hours after the procedure in more than $90 \%$ of the patients. PDPH and accompanying symptoms are selflimiting. They generally resolve within 7 days or less, in $80 \%$ of the cases. In a small minority of cases, the symptoms may persist for weeks or even months [2]. During an episode of PDPH the patient may be completely incapacitated and confined to bed. Obviously this has financial, social and psychological repercussions.

Different prophylactic measures such as: small needle size, the use of Sprotte's needle, reinsertion of the stylet before withdrawing the needle, and direction of the brevel perpendicular to the dura, have all been shown to reduce the occurrence of PDPH [3-6]. If, despite the prophylactic measures, PDPH occurs, epidural blood patch (EDBP) may be a beneficial therapeutic intervention. EDBP has gained popularity as a therapeutic measure for PDPH. It involves the injection of $10-20 \mathrm{ml}$ of autologous blood into the epidural space around the site of the spinal tap. Gormly introduced this technique in the 1960's [1]. He noticed that inadvertent bloody spinal taps were less often complicated by PDPH. He theorised that the epidural bleeding might lead to clot formation over the dural rent, preventing CSF leakage into the epidural space. He therefore continued to treat 6 subjects suffering from PDPH with EDBP, locating the epidural space with the hangingdrop or loss of resistance method. All 6 subjects were relieved of their complaints.

Many observational studies followed; they reported success rates of the EDBP for PDPH between $70 \%$ and $90 \%$ [7-12]. Seven controlled trials concerning prophylactic treatment have been published [13-19]. One of these studies was not blinded [18], three were not randomised [14-16], one was only reported as an abstract [17]. One other study [13] compared prophylactic EDBP versus no blood patch among obstetric patients and reported a high success rate. In this study adverse effects were not mentioned, which prevents firm conclusions. The latest study [19], in which prophylactic EDBP was compared to a sham procedure in a double blind setting, showed no decrease in the incidence of PDPH between the two groups. The effectiveness of prophylactic treatment does not seem to have been established firmly.

Only one randomised and blinded trial concerning the therapeutic effect of EDBP has been reported [20]. In this study 12 patients, suffering from PDPH for more than 4 days, despite conservative treatment following lumbar puncture, spinal anaesthesia or myelography, were randomly allocated to EDBP or sham treatment. In the placebo group none of the patients noted complete relief of pain. In the treatment group 5 of the 6 patients obtained immediate relief. Subsequently placebo group patients were also treated with an EDBP, resulting in complete relief of PDPH in all patients. The size of the study, the crossover effect, and the absence of any documentation regarding the effectiveness of blinding of the observers and patients, makes it difficult to draw firm conclusions from this study.

A Cochrane review on prophylactic and therapeutic blood patching [21] argued that further randomised trials of epidural blood patching must be carried out before the balance of risks and benefits of this intervention can be properly assessed".

Therefore, we decided to conduct a randomised, controlled, clinical trial comparing the efficacy of the EDBP with conservative treatment, consisting of 24 hours of bed rest and adequate fluid intake for the treatment of PDPH.

\section{Methods \\ Inclusion criteria}

To be included in the study, patients should have PDPH longer than 24 hours and not longer than 7 days after a diagnostic spinal tap. Furthermore patients should be aged 18 years or older. Written informed consent is required.

\section{Exclusion criteria}

Excluded are patients with relative contra-indications for lumbar puncture: hemorrhagic diathesis and space-occupying intracranial lesions, and patients with a body temperature over $38^{\circ}$ Celsius.

\section{Design}

This is an observer-blind prospective, controlled and randomised parallel group study.

\section{Active treatment}

Patients allocated to active treatment will receive an EDBP on the day of randomisation. The subject is placed in the lateral position, after which the back is flexed, sterilised and draped. Sterile gloves are used. A needle (Spinocan canule: $0.9 \times 88 \mathrm{~mm} / 206 \times 3.5$ ) is placed in the epidural space, using the loss of resistance technique. Subsequently, 20 cc of blood is than drawn from the antecubital vein, and injected slowly into the epidural space, after which the needle is removed. The subject is held in the supine position for a few minutes, after which there are no further restrictions.

\section{Control treatment}

Conservative treatment consists of the advice to take 24 hours bed rest and drink at least 2.0 litres of fluid a day. The use of painkillers is not prohibited. Treatment with EDBP is not an option during the study period of 7 days, not even when conservative treatment fails. 


\section{Outcomes}

The primary outcome is whether or not headache is present at 24 hours after the start of treatment. Headache is classified on a 4-point scale (no, mild, moderate, severe). Mild headache is defined as: postural headache slightly restricting daily activities. The patient is not confined to bed and there are no associated symptoms. Moderate headache: postural headache confining the patient to bed for part of the day. Associated symptoms are not necessarily present. Severe headache: postural headache where the patient is bedridden for the entire day and associated symptoms are always present. The associated symptoms are: nausea, vomiting, dizziness, hearing loss, hyperacusis, tinitus, photophobia, diplopia, stiffness of the neck and scapular pain [2].

Secondary outcome measures are the presence of headache at day seven after the start of treatment, and the number of days until headache subsides.

\section{Treatment complications}

A systematic assessment of complications of EDBP will be carried out. Back pain will be assessed systematically, and classified as no, mild moderate, severe.

\section{Statistical analysis}

The number of patients with headache at 24 hours after start of treatment will be compared between the two treatment strategies. The effect of treatment on the occurrence of the headache will be expressed as an odds ratio with 95\% confidence interval. Adjustment for the effect of potential confounders, such as age and sex, will be made by multiple logistic regression analysis. The number of days until headache relief will be compared with KaplanMeier survival analysis techniques; observations will be censored at the end of the study period, i.e. 7 days. Adjustments for the effect of potential confounders will be made with proportional hazards regression [22].

\section{Sample size}

A trial with 20 patients in each treatment group will provide us with a power (1- $\beta$ ) of $80 \%$ to detect a relative reduction in number of patients with persisting $\mathrm{PDPH}$ after 24 hours of $50 \%(\mathrm{OR}=12)$ and a power of $99 \%$ to detect a relative risk reduction of $80 \%,(\mathrm{OR}=81$, at the usual significance level $\alpha=5 \%$, taking into account that in approximately $10 \%$ of the patients the PDPH will have resolved spontaneously after one day.

\section{Recruitment of eligible patients}

Patients receiving a diagnostic dural puncture are informed about the possibility of developing PDPH. They all receive written information about the study. A subject suffering from headache after a dural puncture will be advised to contact his physician. The physician evaluates whether the headache is a PDPH or not. When the conclusion is that the subject is suffering from PDPH, he or she is asked to participate. Randomisation is done by a telephone call, by the investigator.

\section{Randomisation procedure}

The randomisation procedure is carried out by one of the investigators ( $\mathrm{RO}$ or FvK). During the telephone contact, while the patient is entered into the computer database the treatment allocation (based on a random number generator) is provided by the computer. The patient cannot be entered twice into the study, nor can the entry be erased.

\section{Ethical considerations and informed consent}

The local medical ethics committee and review board approved this study. Written informed consent will be obtained from all patients, by asking them to return the form by mail or in person, after the randomisation by telephone.

\section{Baseline data}

At baseline, patient demographics age and gender will be registered. Both have been proven to be independent risk factors for the development of PDPH. Clinical characteristics, such as headache characteristics, other complaints, and use of analgesics will be noted. Information concerning needle type, size and re-insertment of the stylet before withdrawing is registered, since all three factors are independent risk factors for the development of PDPH [3-5]. Furthermore the severity of the PDPH is registered on a four-point scale.

\section{Follow-up and blinding}

The follow-up visits are carried out by telephone, by a research nurse at the trial office, 24 hours after randomisation, and at 1 week after randomisation. The research nurse is kept blind to the treatment allocation. At the beginning of the telephone interview the patients are instructed not to inform the observer of the treatment they received. The effectiveness of the blinding will be checked in a sample of 12 patients, by letting the research nurse fill in a forced choice item indicating the treatment allocation.

\section{Discussion}

The EDBP, is widely accepted as the treatment of choice for PDPH. In a review of the literature on this subject however, we found only little evidence to justify its use in general practice [21]. Therefore, we decided to conduct an observer blinded, randomised, controlled, study comparing the therapeutic efficacy of the EDBP to the efficacy of conservative treatment. 


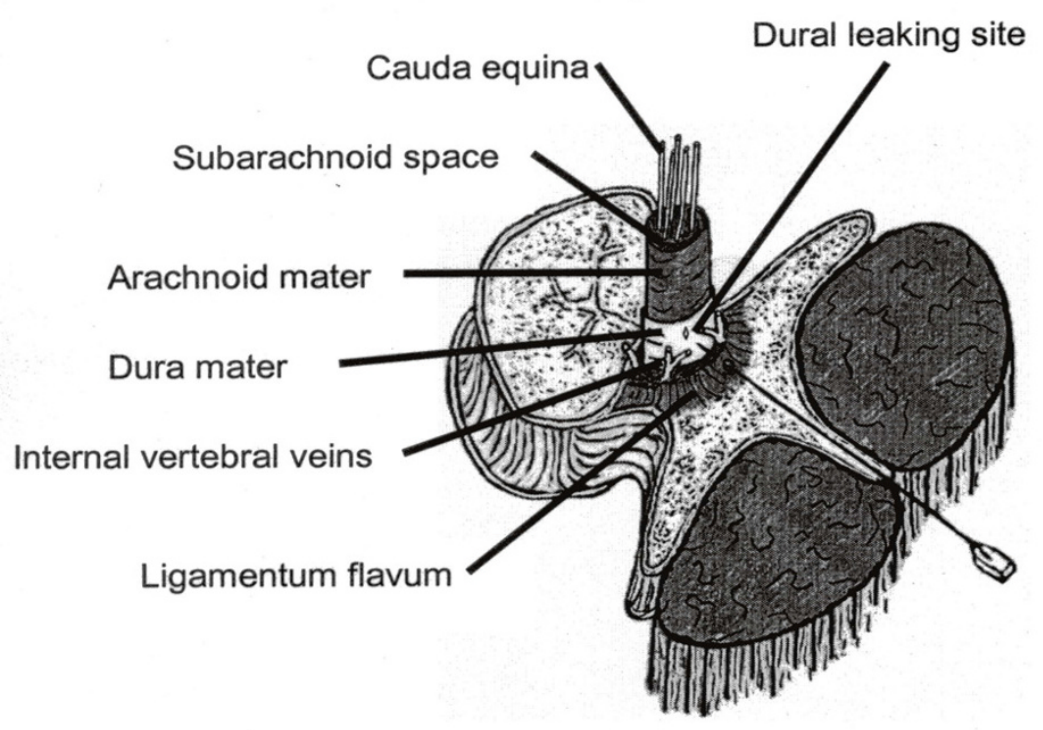

A

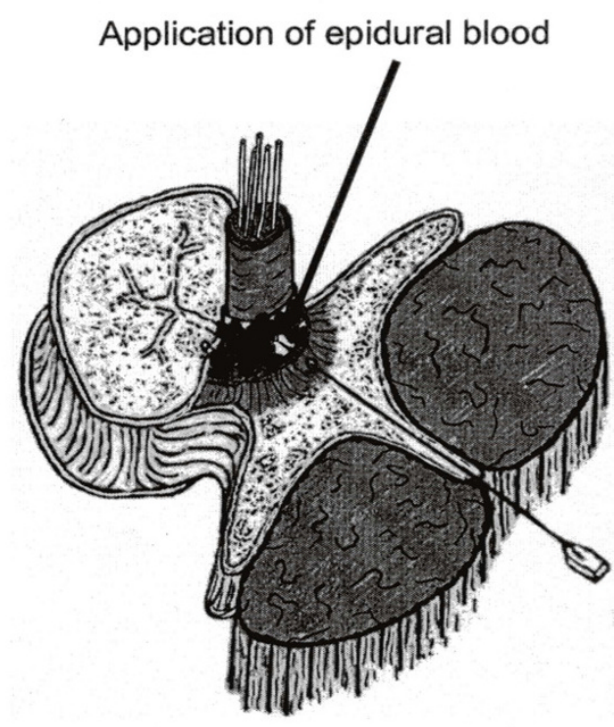

B

Figure I

Schematic section through the vertebral column, showing the cauda equina and its covering membranes with the dural leakage site before $(A)$ and after $(B)$ application of the epidural blood patch.

Our study design not only enables us measure the effectiveness of the EDBP, but also its efficiency. The number of days spent with headache after treatment in the two groups will be characterised as incapacitated-days. Immediate relief of headache, and reduction of the number of incapacitated-days is the ultimate goal of this treatment. By taking into account the adverse effects of EBPD, most notably lower back pain, we will be able to make a more realistic estimate of the overall effect of EPBD.

The observer-blind method we have chosen enables us to compare the two treatment strategies of interest as if they are carried out in normal practise, without the artificial circumstances created by sham treatment, in futile attempts to maintain patient blinding. So a genuine comparison is made between the experimental treatment and normal clinical practise. Because patients are of course aware of the nature of the treatment, the study design limits our ability to assess the placebo effect of the epidural blood patch. One may argue that this may lead to overestimation of the effect of the blood patch. We think that for a treatment of a self/limiting condition this is not really a drawback. Another potential limitation is the small sample size of our study. Although our trial will turn out to be the largest randomised study of therapeutic EDBP ever, a sample size of 20 patients in each treatment group will provide us sufficient power $(1-\beta=80 \%)$ to detect a relative reduction in the risk of PDPH after 24 hours of $50 \%$. Much depends therefore on our assumption that only in approximately $10 \%$ of the patients the PDPH will have resolved spontaneously after one day. Currently, the study is well underway, and we expect to be able to report its results in the end of 2005. 
Table I: Therapeutic studies of EDBP for PDPH

\begin{tabular}{|c|c|c|c|c|c|c|c|}
\hline Author & Number of patients & Type of study & Blinding & $\begin{array}{l}\text { Time window } \\
\text { to inclusion }\end{array}$ & Follow-up & Outcome & $\begin{array}{l}\text { Adverse } \\
\text { effects }\end{array}$ \\
\hline $\begin{array}{l}\text { Safa-Tisseront } \\
200 I[8]\end{array}$ & 527 (504 analyzed) & $\begin{array}{l}\text { Therapeutic, } \\
\text { prospective, non- } \\
\text { randomised, } \\
\text { observational }\end{array}$ & NA & 4 days $(I-53)$ & 15 days & $\begin{array}{l}75 \% \text { complete relief, } \\
18 \% \text { incomplete } \\
\text { relief, } 7 \% \text { failure }\end{array}$ & $\begin{array}{l}\text { Fever in } 3 \\
\text { patients }\end{array}$ \\
\hline $\begin{array}{l}\text { Williams } 1999 \\
{[12]}\end{array}$ & $\begin{array}{l}55 \text { (7 prophylactic, } 4 \text { I } \\
\text { therapeutic EDBP, } 7 \\
\text { conservative treatment) }\end{array}$ & $\begin{array}{l}\text { Retrospective, } \\
\text { non-randomised, } \\
\text { observational }\end{array}$ & NA & $<$ I week & $?$ & $\begin{array}{l}34 \% \text { complete relief, } \\
54 \% \text { incomplete } \\
\text { relief, } 12 \% \text { failure }\end{array}$ & $\begin{array}{l}\text { Back pain in } 3 \\
\text { patients }\end{array}$ \\
\hline Banks 200I [9] & $\begin{array}{l}100 \text { (8I pdph7 } \\
\text { prophylactic, } 58 \\
\text { therapeutic EDBP, } 23 \\
\text { conservative treatment) }\end{array}$ & $\begin{array}{l}\text { Prospective, non } \\
\text { randomised, } \\
\text { observational }\end{array}$ & NA & $0-3$ days & $?$ & $\begin{array}{l}67 \% \text { complete relief, } \\
28 \% \text { incomplete } \\
\text { relief, } 5 \% \text { failure }\end{array}$ & $22 \%$ back pain \\
\hline $\begin{array}{l}\text { Taivainen } 1993 \\
\text { [7] }\end{array}$ & $\begin{array}{l}81 \text { ( } 55 \text { patients } 10 \mathrm{ml} \text {, } \\
26 \text { patients } 10-15 \mathrm{ml} \\
\text { EDBP) }\end{array}$ & $\begin{array}{l}\text { Prospective, } \\
\text { partly } \\
\text { randomised, } \\
\text { observational }\end{array}$ & NA & $0-10$ days & I week & $\begin{array}{l}\text { Initial relief } 91 \% \text {, } \\
\text { permanent relief } 61 \%\end{array}$ & $25 \%$ back pain \\
\hline $\begin{array}{l}\text { Vercauteren } \\
1999[11]\end{array}$ & $\begin{array}{l}190 \text { (I86 EDBP, } 4 \\
\text { atypical symptoms) }\end{array}$ & $\begin{array}{l}\text { Retrospective, } \\
\text { non randomised }\end{array}$ & NA & $\begin{array}{l}>24 \mathrm{~h} \text { after } \\
\text { symptoms }\end{array}$ & I day & $\begin{array}{l}\text { Initial relief } 99 \% \text {, } \\
\text { permanent relief } 73 \%\end{array}$ & $?$ \\
\hline Stride 1993 [10] & $\begin{array}{l}34819 \text { (46 I PDPH, I } 37 \\
\text { EDBP attempted, I } 35 \\
\text { completed) }\end{array}$ & $\begin{array}{l}\text { Retrospective, } \\
\text { non randomised }\end{array}$ & NA & 2 days & $?$ & $\begin{array}{l}\text { Initial relief } 90 \% \text {, } \\
\text { permanent Relief } 64 \%\end{array}$ & $?$ \\
\hline $\begin{array}{l}\text { Seebacher } 1989 \\
{[20]}\end{array}$ & $\begin{array}{l}12 \text { (6 EDBP, } 6 \text { sham } \\
\text { treatment) }\end{array}$ & $\begin{array}{l}\text { Prospective, } \\
\text { randomised }\end{array}$ & Yes & $>4$ days & I day & $\begin{array}{l}\text { EDBP } 83 \% \text { relief sham } \\
\text { treatment } 0 \% \text { relief }\end{array}$ & Back pain \\
\hline
\end{tabular}

\section{Conclusion}

EDBP is accepted as the treatment of choice for PDPH although randomised, controlled data is scarce. Our randomised, observer-blind clinical trial enables us to compare the efficacy of two clinically practiced methods of PDPH treatment; EDBP versus conventional treatment, as they are applied in clinical practise.

\section{List of abbreviations \\ CSF: Cerebrospinal fluid}

EDBP: Epidural blood patch

PDPH: Post dural punction headache

\section{Competing interests}

The author(s) declare that they have no competing interests.

\section{Authors' contributions}

RO participated in the study design and acquisition of data, and drafted the manuscript. FK participated in data acquisition, coordination of the study, and helped to draft of the manuscript. SB participated in the conception of the study, and in data acquisition. DD participated in the conception of the study, data acquisition, and drafting of the manuscript. All authors have seen and approved the final manuscript.

\section{Acknowledgements}

This study was supported by the Netherlands Headache Society. We thank Ron Meier, neurologist, for training us in delivery of the blood patch.

\section{References}

I. Olsen K: Epidural blood patch in the treatment of post-lumbar puncture headache. Pain 1987, 30:293-301.

2. Lybecker $H$, Djerne M, Schmidt J: Postdural puncture headache (PDPH): onset, duration, severity, and associated symptoms. An analysis of 75 consecutive patients with PDPH. Acta Anaesthesiol Scand 1995, 39:605-612.

3. Kang S, Goodnough D, Lee Y, Olson R, Borshoff J, Furlano M, Krueger $\mathrm{L}$ : Comparison of 26- and 27-G needles for spinal anaesthesia for ambulatory surgery patients. Anaesthesiology 1992, 76:734-738.

4. Strupp M, Brandt T, Muller A: Incidence of post-lumbar puncture syndrome reduced by reinserting the stylet: a randomized prospective study of 600 patients. J Neurol 1998, 245:589-592.

5. Strupp M, Schueler O, Straube A, Stuckrad-Barre S, Brandt T: "Atraumatic" Sprotte needle reduces the incidence of postlumbar puncture headaches. Neurology 2001, 57:2310-23I2.

6. Norris MC, Leighton BL, DeSimone CA: Needle bevel direction and headache after inadvertent dural puncture. Anaesthesiology 1989, 70:729-73I.

7. Taivanen T, Pitkanen M, Tuominen M, Rosenberg P: Efficacy of the epidural blood patch for postdural puncture headache. Acta Anaesthesiol Scand 1993, 37:702-705.

8. Safa-Tisseront V, Thormann F, Malassine P, Henry M, Riou B, Coriat $P$, Seebacher J: Effectiveness of epidural blood patch in the management of post-dural puncture headache. Anaesthesiology 200I, 95:334-339.

9. Banks S, Paech M, Gurrin L: An audit of epidural blood patch after accidental dural puncture with a Tuohy needle in obstetric patients. International Journal of Obstetric Anaesthesia 200I, 10:172-I76.

10. Stride P, Cooper G: Dural taps revisited. Anaesthesia 1993, 48:247-255. 
II. Vercauteren MP, Hoffmann V, Mertens E, Sermeus L, Adriaensen H: Seven year review of requests for epidural blood patches for headache after dural puncture: referral patterns and effectiveness of blood patches. Eur J Anaesthesiol 1999, 16:298-303.

12. Williams E, Beaulieu P, Fawcett W, Jenkins J: Efficacy of epidural blood patch in the obstetric population. International journal of Obstetric Anaesthesia 1999, 8: 105-109.

13. Ackerman W, Jeneja M, Kaczorowski D: Profylactic epidural blood patch for prevention of postdural puncture headache in the parturient. Anaesthesiology 1990, 17:45-49.

14. Trivedi N, Eddi D, Shevda K: Headache prevention following accidental dural puncture in obstetric patients. J Clin Anesth 1993, 5:42-45.

15. Colonna-Romano $P$, Shapiro B: Unintentional dural puncture and prophylactic epidural blood patch in obstetric. Anesth Analg 1989, 69:522-523.

16. Heide W, Diener H-C: Epidural blood patch reduces the incidence of post lumbar puncture headache. Headache 1990, 30:280-28I.

17. Lowenwirt I, Cohen S, Zephyr J, Hamer R, Hronkova B, Rovner J: Can prophylactic epidural blood patch reduce the incidence and severity of postpartum dural puncture headache in obstetrics? [abstract]. Anesth Analg 1998, 86(2S):378s.

18. Sengupta $P$, Bagley G, Lim M: Prevention of postdural puncture headache after spinal anaesthesia for extracorporeal shockwave lithotripsy. An assessment of prophylactic epidural blood patching. Aneaesthesia 1989, 44:54-66.

19. Scavone B, Wong C, Sullivan J, Yaghmour E, Sherwani S, McCarthy R: Efficacy of a prophylactic epidural blood patch in preventing post dural puncture headache in parturients after inadvertent dural puncture. Anaesthesiology 2004, 10 I: | 422- I 427.

20. Seebacher J, Ribeiro V, LeGuillou JL, Lacomblez L, Henry M, Thorman F, Youl B, Bensimon G, Darbois Y, Bousser MG: Epidural blood patch in the treatment of post dural puncture headache: a double blind study. Headache 1989, 29:630-632.

21. Sudlow C, Warlow C: Epidural blood patching for preventing and treating post-dural puncture headache (Cochrane Review). 3rd edition. Chisester, UK: John Wiley \& Sons, Ltd; 2004.

22. Cox DH: Regression models and life tables. J R Statist Soc 1972, B34: $187-220$.

\section{Pre-publication history}

The pre-publication history for this paper can be accessed here:

http://www.biomedcentral.com/1471-2377/5/12/prepub

\section{Publish with Biomed Central and every scientist can read your work free of charge}

"BioMed Central will be the most significant development for disseminating the results of biomedical research in our lifetime. "

Sir Paul Nurse, Cancer Research UK

Your research papers will be:

- available free of charge to the entire biomedical community

- peer reviewed and published immediately upon acceptance

- cited in PubMed and archived on PubMed Central

- yours - you keep the copyright

Submit your manuscript here:

http://www.biomedcentral.com/info/publishing_adv.asp
BioMedcentral 